\title{
Ordenando o Paraíso: a Paisagem da Cidade do Rio de Janeiro nos Cartões-Postais (1900-1930)
}

\section{Ordering Paradise: the Landscape of the City of Rio de Janeiro on Postcards (1900-1930)}

\author{
Rachel de Almeida Moura \\ Universidade Federal do Rio de Janeiro \\ Rio de Janeiro, Brasil
}

Resumo: Tendo como objetivo interpretar e compreender a construção simbólica que se fez da imagem da cidade do Rio de Janeiro a partir da leitura das paisagens cariocas apresentadas em seus cartões-postais, o presente trabalho apresenta uma reflexão sobre as representações de paraíso tropical e cidade moderna que circulam através dos cartões-postais do período de 1900-1930 da cidade do Rio de Janeiro. É a ordenação do paraíso que faz do Rio de Janeiro a cidade maravilhosa e se torna sua marca até os dias de hoje.

Palavras-chave: Rio de Janeiro; Paisagem; Cartão-Postal.

\begin{abstract}
The objective of this work is to interpret and understand the symbolic construction of the image of the city of Rio de Janeiro, based on the reading of the Carioca landscapes presented in postcards. A reflection on the representations of tropical paradise and the modern city is presented using postcards for the period 1900-1930. The dominant theme identified is that of a distinctive ordering of paradise in which Rio de Janeiro is protrayed as the marvelous city and becomes its mark to this day.
\end{abstract}

Keywords: Rio de Janeiro; Landscape; Postcard.

\section{Introdução}

A ideia de se enviar um cartão-postal no lugar de uma carta comum foi aceita pela primeira vez em 1869 pelo Império austro-húngaro. O cartão (correspondenz-Karte) media 85 x $122 \mathrm{~mm}$, tendo uma face exclusiva para o endereço e a outra face branca, para ser escrita a mensagem. Seu objetivo principal era diminuir os custos do serviço postal, servindo para comunicações breves (GORBERG, 2002).

A novidade foi rapidamente aceita pelo público e se expandiu para outros países. Segundo Gorberg (2002), no dia do lançamento, em Berlim, foram vendidos 45.000 cartões-postais e, no decorrer do ano, a Alemanha vendeu cerca de 10 milhões. Já em 1899, com uma população de 50 milhões, a Alemanha registrou 88 milhões de cartões

\footnotetext{
' Doutoranda do Programa de Pós-Graduação em Geografia da UFRJ. rachel_amoura@yahoo.com.br.
} 
postados. No Brasil, a mesma ideia se concretizou com nome de bilhete postal. O primeiro bilhete postal produzido aqui data de 1880 .

Em 1891, os postais passaram a ter a fotografia como imagem, o que introduziu um caráter artístico a este produto e facilitou a rápida expansão de seu uso pelo mundo, permitindo a fixação e divulgação do ambiente onde o homem vivia.

No Brasil, os primeiros decênios do século XX corresponderam à Idade de Ouro do Cartão-Postal e a Belle Époque da capital, ou seja, o Rio de Janeiro de Pereira Passos estava exatamente no momento auge da procura dos cartões-postais (GORBERG, 2002).

Congregando os interessados, associações de cartofilia surgiram por todo o mundo. No Brasil, fundou-se em junho de 1904 a Sociedade Cartophilia Internacional Emanuel Hermann. Essas associações publicavam boletins com o nome dos sócios e seus endereços para facilitar a troca de cartões-postais, prática muito comum nessa época. Revistas especializadas também eram numerosas no mundo a fim de atender as necessidades dos colecionadores (GORBERG, 2002).

Meio de correspondência e objeto de coleção, os postais foram produzidos em série e numerados por casa ou editores. O prazer da coleção e a vinculação das imagens em um meio de grande circulação social - o correio - tornaram o postal um grande divulgador de ideias, valores e representações sobre o espaço que nele eram retratadas. São, pois, retrato de uma época, fonte de memória, ao mesmo tempo que ajudam a construí-la.

No cartão-postal está gravada a cidade do passado, sua paisagem em um ponto de vista retratado pela lente de um fotógrafo. Uma posição no ato de fotografar que revela ideias sobre aquilo que se observa, ao mesmo tempo em que ao circular pelo Brasil e pelo mundo, o postal contribui para construção de narrativas sobre a cidade.

Com base nesta argumentação, nosso trabalho terá como objeto de estudo os cartões-postais que representam a natureza e a cidade do Rio de Janeiro no período de 1900 a 1930. Escolhemos esse recorte temporal por ser o período da belle époque dos cartões-postais.

Foram selecionados 635 cartões-postais de 1900 a 1930, na Biblioteca Nacional e na Biblioteca Pública do Estado do Rio de Janeiro e do acervo pessoal. Também trabalharemos com postais encontrados em livros e ainda postais do acervo particular da autora deste trabalho. Para esse trabalho foram reproduzidos 9 postais. Selecionamos somente os postais que representam iconograficamente a cidade, onde, portanto, destaca-se a paisagem urbana.

Diante disso, tendo o cartão-postal como objeto de estudo, nosso objetivo principal é interpretar e compreender a construção simbólica que se fez da imagem da cidade do Rio de Janeiro a partir da leitura das paisagens cariocas apresentadas em seus cartões-postais.

\section{Metodologia}

Cosgrove e Duncan são até hoje referências para o estudo da paisagem entendida como imagem. O primeiro autor reflete sobre a iconografia e iconologia da história da arte, enquanto o segundo pensa a paisagem como um texto através da matriz conceitual da semiologia. 
Seemann (2009), Novaes (2011 e 2013), Driver (2013), entre outros, apresentam mais recentemente como referencial teórico para o desenvolvimento de suas metodologias a obra de Rose (2001) Visual Methodologies. Para Driver (2013, p.213) seu trabalho "influenciou consideravelmente o modo com que a pesquisa no campo visual é ensinada e praticada nas ciências sociais". Nele, a autora afirma que uma teoria e metodologia sobre a imagem não são explícitos e apresentam perspectivas metodológicas diferentes, todas elas de raiz interpretativa, para as diversas formas de imagens existentes: pintura, filme, fotografia, anúncios publicitários, etc. Dentre as abordagens metodológicas de Rose (2001) estão presentes as já utilizadas por Cosgrove e Duncan. A autora acrescenta outras metodologias, tais como: a intepretação composicional, análise de conteúdo, psicanálise e análise do discurso.

Rose (2001) sugere três aspectos sobre a imagem para a sua compreensão crítica, a saber: a tecnologia que produziu ou melhorou a imagem, a composicionalidade da imagem (conteúdo, cor e organização espacial) e as relações sociais que a produziram ou que detêm os códigos sociais necessários a sua interpretação. Esses aspectos poderão ser entendidos por meio das diversas metodologias visuais desenvolvidas ao longo do seu livro.

Seguindo as sugestões de Rose (2001), a composicionalidade é a modalidade mais importante para entender os efeitos de uma imagem, pois o acordo formal dos elementos de uma imagem irá ditar a forma como ela é vista por seus públicos.

A autora apresenta uma metodologia "composicional interpretation" visando identificar símbolos visuais convencionais (iconografia de Panofsky), bem como os valores e significados presentes no uso de determinadas técnicas, como, por exemplo, cores quentes e frias que sugerem efeitos de atração e distância, respectivamente, ou o claro e o escuro que sugerem atmosfera de paz e medo (iconologia de Panofsky). Dedica-se aos aspectos da organização espacial e de como os elementos icônicos estão convencionalmente estruturados na composição. Por fim, apresenta as diferentes perspectivas geométricas e seus efeitos nos planos da imagem. Seu entendimento sobre a composicionalidade da imagem, portanto, é uma mescla das abordagens metodológicas advindas da história da arte e da semiologia.

Rose (2001) salienta que a semiologia elaborou um vocabulário analítico para descrever como os signos fazem sentidos (ícone, índice e símbolo) que pode ser aplicado a todo os tipos de materiais visuais. Em especial, a fotografia dos cartões-postais comunica através de mensagens não verbais. Sendo trabalho humano de comunicação, pauta-se, enquanto tal, em códigos convencionalizados socialmente, possuindo para Mauad (1996) um caráter conotativo que remete às formas de ser e agir do contexto no qual estão inseridas como mensagens.

Essa substancial bagagem teórica, aliada à necessidade de entendimento do contexto de Panofsky, tem como resultado uma ficha que compreenda dados de identificação do postal e, ainda, que apresente o registro fotográfico propriamente dito.

Mauad (1996) defende a fotografia como documento dentro da abordagem semiológica de "forma de conteúdo" e de "forma da expressão". Assim, propõe o trabalho com fotografia a partir de uma ficha de análise. Em nosso caso, pensamos numa ficha para os postais dividida em duas partes: na primeira conta-se com dados gerais, uma 
pré-iconografia, tais como: autor, ano do postal, bairro da cidade do Rio de Janeiro e localização na base de dados (Biblioteca Nacional - BN, Biblioteca Pública do Estado Rio de Janeiro - BPERJ e Acervo Pessoal - AP).

Já na segunda parte da ficha deve-se indicar os elementos formais da fotografia como forma, linha, proporção, cor, espaço e tomada, entre outros, para que através da técnica utilizada seja feita uma interpretação dos sentidos da imagem. É preciso ainda identificar pessoas, objetos e natureza retratados e seus atributos; elementos incomuns, ou repetitivos, símbolos e índices de alguma imagem.

Se faz necessário ainda prestar atenção ao enquadramento e à organização espacial dados pelos tipos de plano, ângulo e lado do ângulo, a saber: os tipos de plano principais são: grande plano geral (GPG) - aquele em que plano é o ambiente. O sujeito ou objetos também dimensionam o plano, mas estão dominados pelo ambiente; plano geral (PG) situa o objeto no ambiente, integração entre objeto e ambiente. O ângulo visual é bem aberto; plano médio (PM) - é descritivo, o objeto é enquadrado por completo, mas ainda há espaço para o ambiente; plano pequeno (PP) - objetivo de enquadrar apenas o objeto e plano do detalhe (PD) - isola objeto do ambiente.

Já os tipos de ângulos são: plongée - palavra francesa que significa mergulho, isto é a câmera está acima do objeto a ser fotografado, voltada para baixo; contra-plongée - a câmera está "abaixo" do objeto e voltada para cima e normal - no mesmo nível do objeto. Por fim, o lado do ângulo, ou pode ser, frontal - em linha reta com o objeto; 3/4 - em aproximadamente 45 graus com o objeto ou perfil, isto é em ângulo de 90 graus com o objeto.

\section{Ordenando o Paraíso}

Complexo de signos sejam eles formais (a forma do objeto), linguísticos (o nome das ruas, propagandas) estéticos (fachadas, jardins, iluminação), entre outros, a cidade do Rio de Janeiro, compreendida enquanto sistema de comunicação é, em seu contexto, aqui analisada no recorte temporal escolhido para esse estudo - 1900 a 1930 -, através dos cartões-postais como suporte para narrativas imagéticas.

Buscamos entender as imagens dentro do número de postais selecionados, tendo como base o conceito de paisagem - Landschaft - ou seja, voltamos nosso olhar para a imagem dos cartões-postais a fim de encontrar na paisagem da cidade elementos que nos indiquem a relação do homem com a natureza, o "complexo natural total", conceito assim definido por Freitas, Peres e Rahy (1999) ao compreenderem que foi construído sob a influência do racionalismo positivista de um lado e do idealismo romântico, de outro.

O complexo natural total inclui o homem na paisagem e a caracteriza como um fenômeno da esfera da representação, a paisagem só existe na relação específica entre o homem e o mundo, não estando, para Lourenço (2002, p.112), pressuposta no sujeito; mas manifestando-se com o mundo, pois "é só nessa relação específica, o homem e o mundo transformam-se em paisagem".

Diante disso, os cartões-postais apresentam imagens que expõem duas grandes representações: o paraíso diretamente relacionado à ideia de natureza; e o progresso, referindo-se à cidade cosmopolita que se forjava no período da Primeira República. 
Tais ideias nos cartões-postais são encontradas como conteúdo dos signos. Nos postais a seguir (Figuras 1 a 11) estão presentes signos que remetem à beleza e à perfeição: a mata, a água, a rocha, criações divinas que se mesclam na cidade do Rio de Janeiro, lócus do desenvolvimento humano. A cidade insurge entre o mar e a montanha, no postal abaixo.

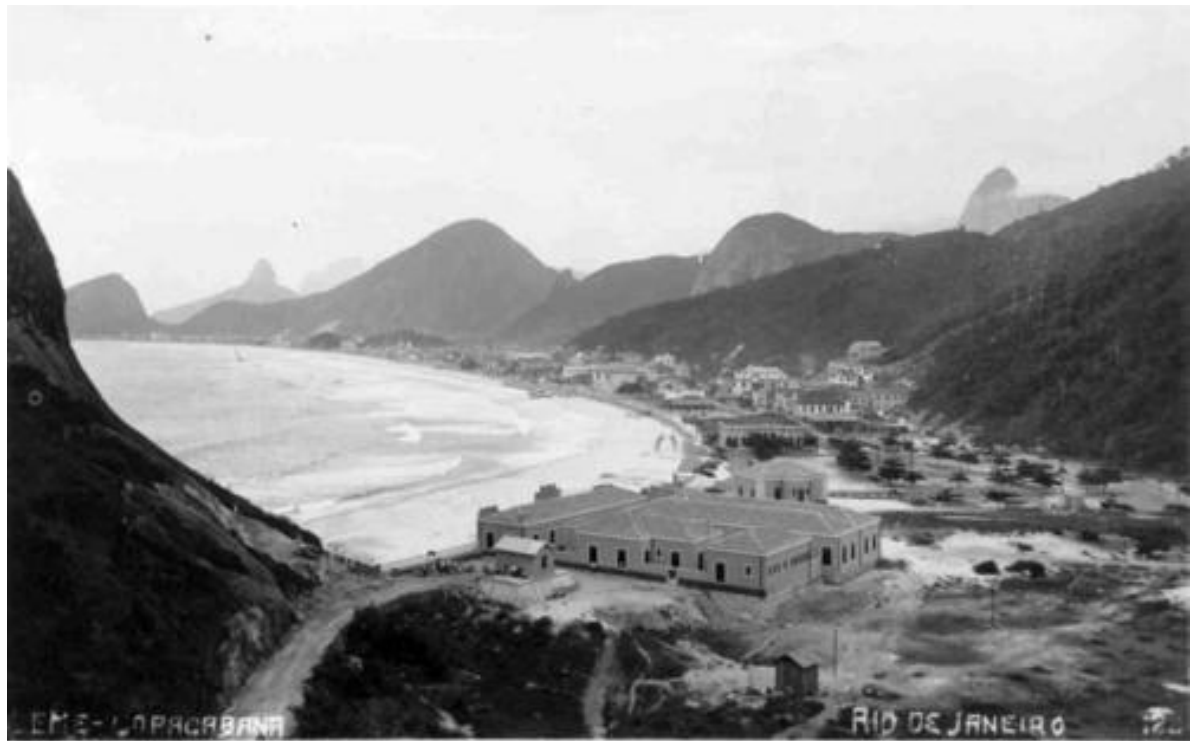

Figura 1 - Postal do bairro do Leme, Copacabana - s.a., s.d. BPERJ.

O pensamento sobre o trópico não se restringe apenas a uma categoria geográfica; pode ser entendido, também, no plano cultural e sociológico, bem como tratou Levi Strauss em sua obra Tristes Trópicos. Nela, o trópico representou uma série de ideias construídas no período das grandes navegações.

Elementos de uma tropicalidade como um grandioso céu límpido, natureza abundante, ou até mesmo signo que se repete nas imagens: a palmeira (presente em quase $76 \%$ dos postais) denota a imagem de uma cidade que tem na sua particularidade a beleza natural e tropical dominada pela beleza da obra humana.

Sendo uma prática comum os postais serviam também para propaganda de produtos, conforme foi demonstrado por Gorberg (2002). Assim, empresas escolhiam paisagens de cidades para ajudar no marketing de seus produtos. Copacabana e outros bairros da cidade do Rio de Janeiro serão intensamente representados com essa finalidade, sempre de preferência em ângulo do tipo grande plano geral ou plano geral e a palmeira aparece em algum dos planos como um signo da tropicalidade (Figura 2). 


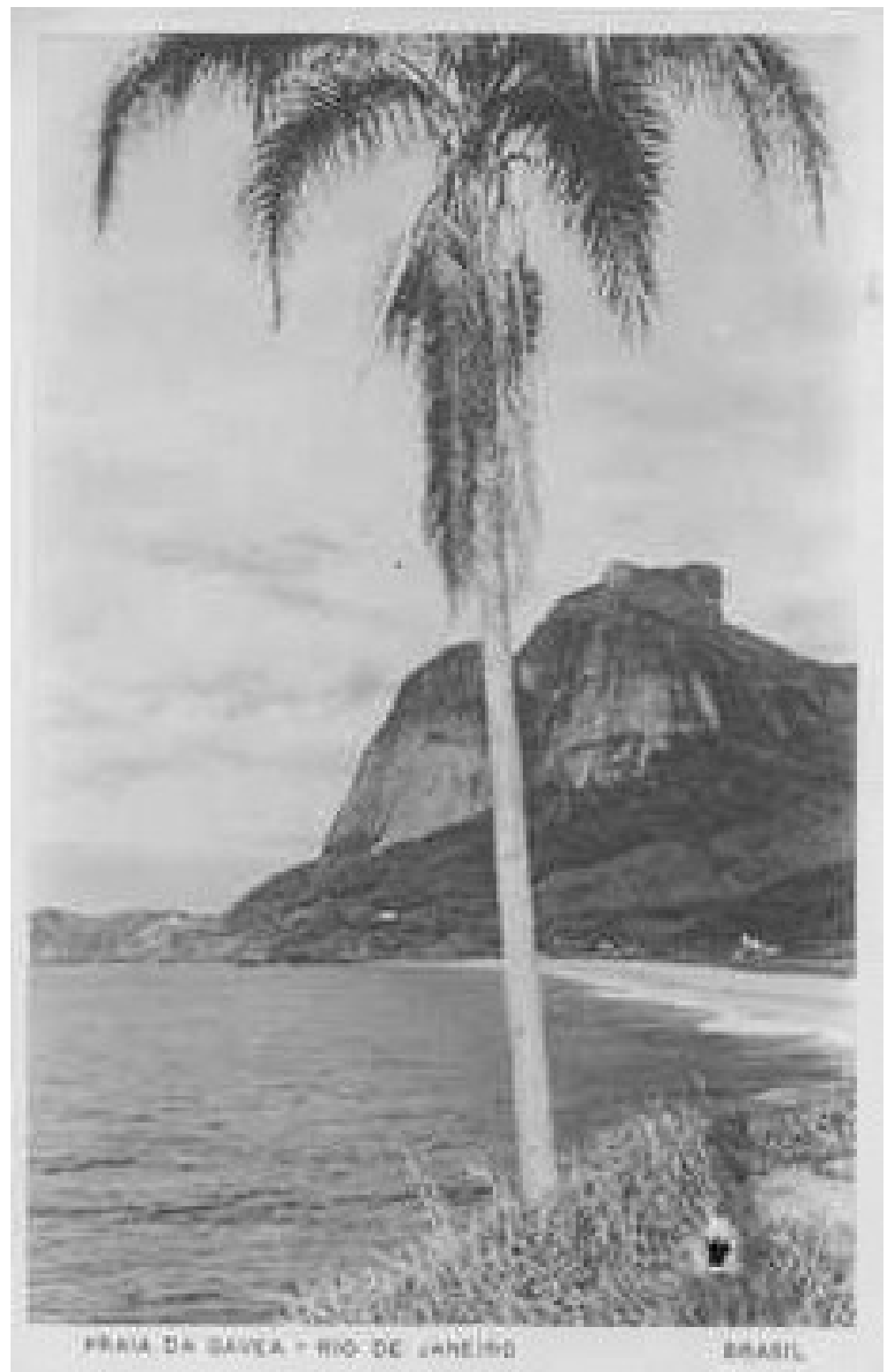

Figura 2 - Postal da Vista Chinesa

Rio de Janeiro, s.a., s.d., ao redor de 1905. AP.

Toda a simbologia da palmeira foi forjada a partir do paisagismo do Jardim Botânico. Criado por D. João VI, em 13 de junho de 1808, o Jardim Botânico refletiu uma prática de cultivo de árvores nas cidades europeias que se impunha desde o século XVIII, carac- 
terizou-se como passatempo das elites que desenvolveram o costume de passear pelas verdes alamedas, bem como possuiu a função prática de servir aos estudos científicos, revelando aqui, mais uma vez, a ligação das imagens de natureza exótica e utilitária.

Adaptado para os trópicos, em nosso Jardim Botânico passou a ser comum a execução de cerimônias cívicas repletas de valores simbólicos. Uma delas ficou marcada no imaginário da população: o rei, em 1809, plantou uma árvore que deveria significar a força e o vigor da monarquia. A árvore escolhida foi a elegante e imponente palmeira Roystonae oleracea, que pode chegar a até 40 metros de altura, criando o mito aristocrático da Palmeira Mater (VALLE, 2005).

O poder imperial apropria-se de um signo característico do ambiente tropical, sobretudo da opulência e grandiosidade da natureza e acrescenta a esse valor a opulência e grandiosidade do império por meio da plantação das palmeiras filhas (germinadas da palmeira mater) no Jardim Botânico. Assim, de acordo com Valle (2005, p.122), "a partir daí, a suposta aristocracia do recém-criado Império brasileiro, passou a plantar a referida palmeira em suas residências e fazendas [...] tornou-se, desse modo, um inequívoco símbolo nacional [...]".

Desta forma, perpetuado com os barões de café, o símbolo da Palmeira será um elemento tropical diferenciador da paisagem nacional e tornar-se-á, na República, um padrão estético paisagístico de representação do mundo tropical, a partir da Cidade do Rio de Janeiro.

Além do signo da tropicalidade, representado pela palmeira, é importante analisar as escalas das fotografias que resultam em cartões-postais em perspectiva de grande plano geral, onde sujeito ou objetos também dimensionam o plano, mas estão dominados pelo ambiente e pelo plano geral que situa o objeto no ambiente, integração entre objeto e ambiente. O ângulo visual é bem aberto. Apresenta espaços exteriores ou interiores de grandes proporções. Esses dois tipos de ângulos permitem, de acordo com Pereira (2007, p. 3) que:

No registro, o fotógrafo dialoga com alguns aspectos da noção de "sublime", um conceito de representação da noção de natureza que, além da categoria do "belo", se tornou um padrão difundido por meio da iconografia e de relatos produzidos pelos viajantes.

A noção de sublime ajudou a construir um imaginário de paraíso tropical para o Rio de Janeiro, que aparece nos postais já mostrados e em diversos outros em que a tomada da fotografia leva ao extremo a relação da imensidão da natureza com a pequenez do homem. Quando o homem aparece é um objeto em detalhe, geralmente na parte inferior do postal ou no primeiro plano que está contemplando o mar. Ou ainda aparece um homem num ponto mais elevado, mais ainda como um detalhe no enquadramento a contemplar a natureza (como nos impõe a estética do ideal romântico).

Assim, temos panoramas que retratam um Rio de Janeiro tropical, quase desabitado. Isto, por sua vez, nos remete a um imaginário do paraíso em bairros como a Gávea, Lagoa Rodrigo de Freitas, Copacabana, entres outras localidades que aparecem nos postais, guardando-se as devidas proporções de habitações e desenvolvimento em relação ao 
início do século passado. Encontramos vários postais da Lagoa Rodrigo de Freitas desabitada, num período anterior aos aterros para a construção da Avenida Epitácio Pessoa durante a administração do prefeito Carlos Sampaio. Ou ainda, postais de Copacabana da primeira década do século XX, como uma praia quase deserta. Segundo Rabha (2006), no início do século XIX, Copacabana era considerada muito mais uma estação de veraneio e convalescença do que residência permanente, tendo, portanto, sua origem como um imenso areal.

Esta mesma ideia não denota uma depredação do local. Copacabana não é vista como "o fim do mundo", ou o "lugar inóspito". Por estar sendo representada nas lentes dos fotógrafos, Copacabana é paradisíaca, localizada entre a cadeia de montanhas e o oceano aberto; só mais tarde se tornaria perto do centro da cidade, espaço civilizado, por isso, será o próximo espaço a ser dominando, a ser marcado pela civilização dos trópicos. Copacabana é um recorte da cidade que muito se repete nos postais.

Pereira (2007) contribui para essa reflexão ao apresentar que somente a partir de 1907 cenas com atributos da urbanização transformaram os postais de Copacabana em vetores para a expansão imobiliária, conforme o postal da Figura 3.

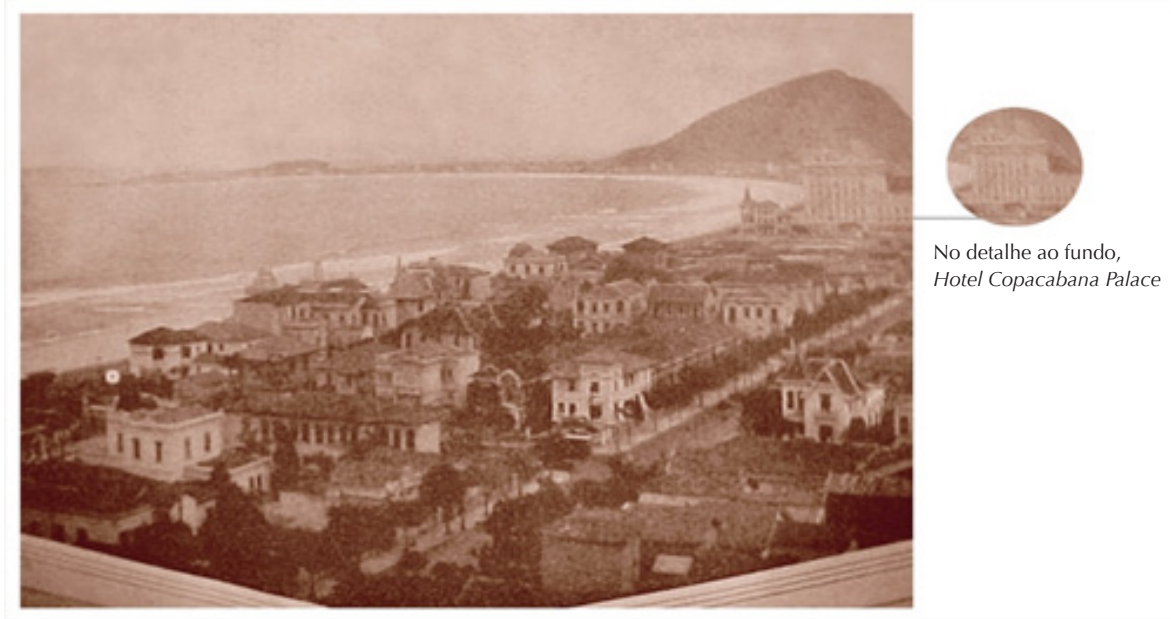

Figura 3 - Postal de Copacabana, s.a., s.d., por volta de 1923. BN.

Veja no canto direito superior o Hotel Copacabana Palace inaugurado em 1923. Para Lessa (2000), sua construção em pleno bairro de Copacabana quis significar a prioridade carioca de exibir a natureza sob seu domínio. Note ainda, em destaque, a Rua Copacabana que futuramente será chamada Avenida Nossa Senhora de Copacabana, consolidada em 1920, quando se inicia seu processo de verticalização que permitirá uma maior apreciação do panorama do bairro.

Considerando os aspectos técnicos da fotografia, pode-se destacar que em contraposição à linha reta da rua, a praia também é mostrada, em segundo plano pela perspectiva 
diagonal que valoriza as formas da natureza. Temos um novo simbolismo sobre o espaço da praia que será também apropriado pelos vetores da expansão imobiliária na cidade.

Desta forma, o novo simbolismo ocorre a partir da mudança na concepção que excluía o espaço da praia da vida social. Corbin (1989) desenvolve em sua obra O Território do Vazio: a Praia e o Imaginário Ocidental, a transformação da relação do homem com o oceano. Antes entendido como algo terrível, repugnante e perigoso, torna-se, pouco a pouco, um espaço de vivência; inicialmente pelas vantagens medicinais de que a água teria a oferecer e, posteriormente, no século XIX, como um espaço de lazer, resultado de uma renovação na concepção estética e no discurso sobre a necessidade do homem ter momentos para o lazer.

Para Lessa (2000) a redescoberta do mar e da praia é um fenômeno extremamente importante para a cidade do Rio de Janeiro. As praias serão lidas sob essa nova ótica a partir da década de 1930, transformando-se em símbolo de beleza e conotando ideias de bem-estar, pois de acordo com Lessa (2000) "o Rio pela costa, ao redescobrir o mar, constrói junto à pertinência à cidade, a ideia de sua abertura ao mundo pela superfície das águas".

Lessa (2000) está se referindo a dois aspectos da relação da cidade com o mar. O primeiro trata da representação sobre a praia que também será apropriada pelas imobiliárias, sobretudo, a partir da década de 1930, promovendo seu desenvolvimento, ao discursar sobre o status que o morar à beira mar seria capaz de oferecer. $\mathrm{O}$ segundo, refere-se ao fato do Rio de Janeiro voltar-se para o mar para ter no comércio exterior grande fonte de seu desenvolvimento. Encontramos alguns postais que abordam esse aspecto. A maioria representa o porto, após a reforma de Pereira Passos, na perspectiva panorâmica.

Desta forma, signos que se repetem nos postais exprimem a ideia de paraíso para o Rio de Janeiro, mas com vestígios que indiquem a ordenação pelo trabalho humano. Atrelado a isso para a construção da nação brasileira, a natureza teve um papel importante à medida que o governo, juntamente com a literatura romântica, promoveu a exaltação de uma natureza nacional, onde é possível evocar uma nação através de sua paisagem, ou seja, a ideia da terra como pátria.

O homem deixa de ser elemento integrante da fotografia, apenas como observador da natureza (Figura 4), e torna-se, ele mesmo, um agente da paisagem. Nesse sentido, os postais também foram elementos para a divulgação das melhorias dos bairros da cidade.

Ademais, essas imagens contribuíram para espalhar no imaginário da população colecionadora a oposição civilização X natureza selvagem/intocada, reafirmando a ideia de uma sociedade rumo ao progresso. Contudo, não se constitui uma civilização idêntica ao modelo europeu, mas ela se diferencia por ter sido forjada numa paisagem muito próxima a um "paraíso tropical". Elementos de uma civilização em profunda relação com a concepção francesa de sociedade são revelados em diversos signos. A "francofilia" experimentada pelos cariocas neste período resulta num projeto de cidade - "a Paris dos trópicos".

Na Figura 4 temos à frente o outeiro da Glória e Santa Tereza no morro à direita. A rua é tomada em perspectiva central e os jardins (na foto em questão, os jardins do Palácio Monroe, que já não mais existem) mostram a influência francesa de cidade. 


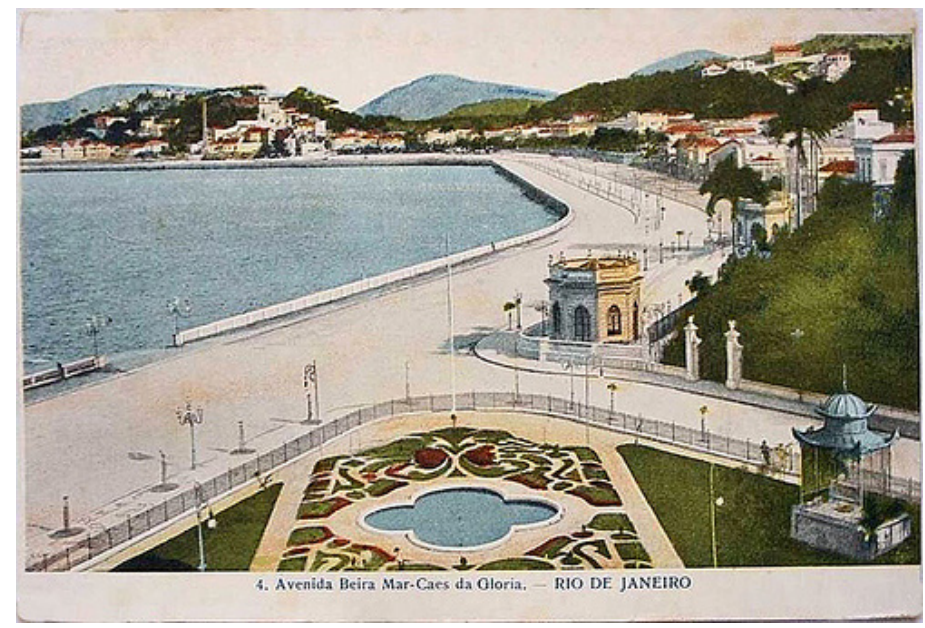

Figura 4 - Postal da Av. Beira Mar, Glória, s. a., s.d., por volta de 1905. BN.

O fotógrafo, não identificado nesse postal, posiciona-se no limite da Avenida Central. Ao ressaltar o requinte do trabalho de composição geométrica no chão, indica um sinal de investimento e arte no trato com o espaço público. O mesmo pode ser dito dos diversos postais encontrados que destacam os jardins da Avenida Beira-Mar. Os jardins foram responsáveis pela higiene e pelo lazer da vida urbana, de tal forma que eram molduras do urbanismo e da modernidade. A natureza nos jardins está domesticada e adaptada ao desenho urbano. O Passeio Público foi o primeiro local de lazer da cidade.

Os jardins do Passeio Público sofreram diversas reformas ao longo das décadas, uma delas pelas mãos do francês Glaziou em 1861, discípulo de Jean Charles A. Alphand, coordenador das obras de paisagismo da reforma urbana de Haussmann, em Paris. Esse fato evidencia as estreitas ligações entre a cidade e a França (MACHADO, 2008).

Outro jardim bastante retratado pelos fotógrafos e presente em vários cartões-postais foi a Quinta da Boa Vista (Figura 5). Coberta de exuberante vegetação, a Quinta da Boa Vista era um oásis na feia, alagadiça e deserta zona praieira que seguia depois da Gamboa. Reformado para residência real, a Quinta foi ampliada e seus jardins embelezados no reinado de D. Pedro II, conforme nos relata Brasil (1965). Todavia, foi, por excelência, um lugar do Império. Mesmo assim, seus jardins também aparecem nos cartões-postais.

$\mathrm{Na}$ verdade, ao reformar os jardins, em 1909, buscou-se valorizar as características do trabalho francês de Glaziou, mas se modificou o sentido daquele espaço, pois a República democratizou o parque do rei da cidade antiga como jardim urbano aberto ao povo e nesse novo jardim transformou a moradia do rei no Museu Nacional. Nesse sentido, de acordo com Lessa (2000, p.200) "a paisagem urbana da cidade moderna apropria-se, redefinindo-a, da coleção de signos da cidade antiga e agrega outros tantos deliberadamente construídos como ícones demonstrativos do progresso e vanguardismo". 
A partir da técnica fotográfica da Figura 5, temos a perspectiva em diagonal dada pelo ângulo 3/4 que causa a impressão de infinitude da Quinta da Boa Vista, e realça em todos os planos da fotografia o trabalho de Glaziou. A mesma técnica é utilizada para diversos postais da Avenida Central (hoje intitulada Av. Rio Branco), como por exemplo, na Figura 6. Isto por sua vez constrói significados referentes a sua atmosfera cosmopolita, condizente com uma grande cidade.

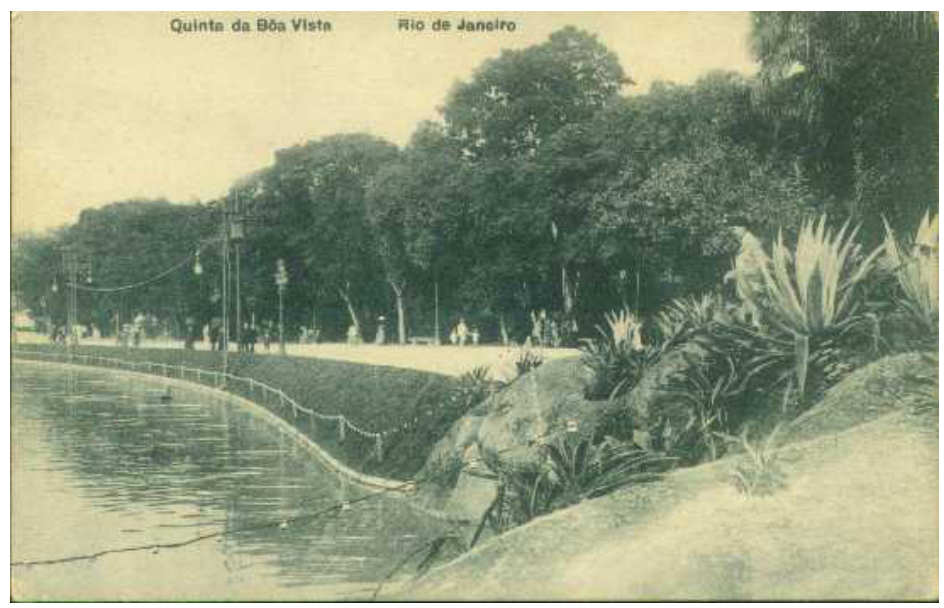

Figura 5 - Postal da Quinta da Boa Vista, RJ. Alexandre Ribeiro, 1917. BN.

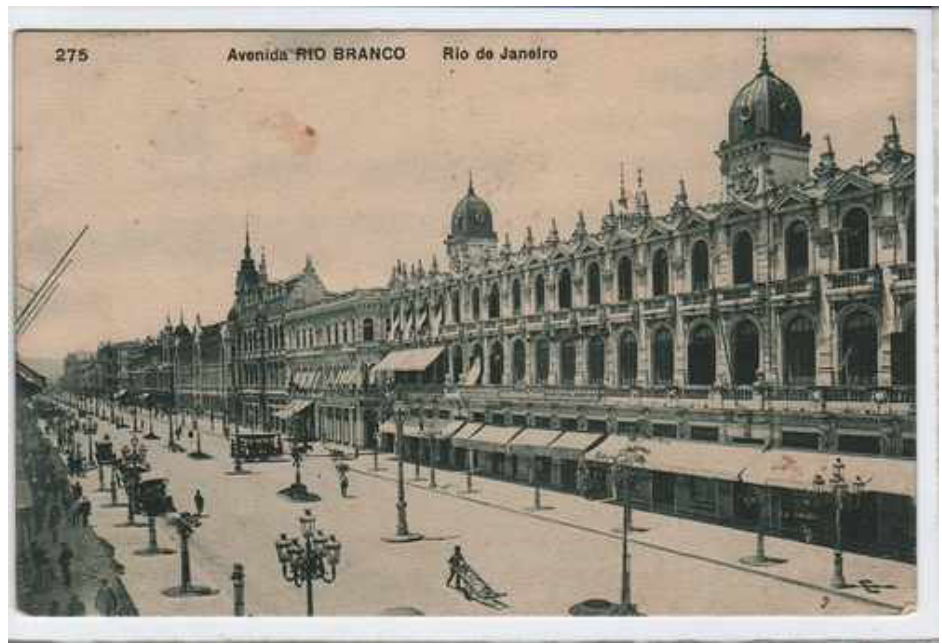

Figura 6 - Postal da Av. Rio Branco, RJ, s.a., sd., sem autor, por volta de 1910 AP. 
A Avenida Central é o principal símbolo da cidade nesse período e foi retratada de diversos ângulos. A amplitude do espaço, dada pelo ângulo da fotografia (Figura 6), também ressalta o contraste desse espaço com a limitação dos corpos na rua. O caminho do progresso, representado pela abertura das grandes avenidas, nos mesmos moldes que os boulevards na França. Nesse sentido, Lessa (2000) ressalta que a construção da grande Avenida Central não teve nada a ver com os interesses em adaptar o país para a vinda do automóvel. Mas, é claro que, alguns anos depois da sua construção, os automóveis serão um aspecto marcante na paisagem carioca.

A necessidade de adequar a forma urbana carioca à criação, concentração e acumulação do capital está expressa nestes cartões-postais que mostram a construção da Avenida Central e de outros pontos da cidade durante o período de grandes transformações urbanísticas no centro do Rio de Janeiro, a chamada Reforma Pereira Passos.

Há ainda diversos cartões-postais que valorizam a arquitetura da cidade. Todo o destaque serve para mostrar na arquitetura a magnitude e grandiosidade da civilização capaz de construir equipamentos urbanos esplendorosos. Edifícios que compõem sobretudo a Avenida Central aparecem em ângulo frontal e contra-plongée (que aumenta seu tamanho). São elementos que indicam formas modernas e uma representação de estruturas de poder construídas num processo de importação de formas e de reprodução mimética de ícones espaciais e arquitetônicos.

Os prédios aparecem em vistas frontais, chapadas, recortadas de sua paisagem de fundo de maneira a permitir ver cada detalhe ornamental das fachadas. A perspectiva adotada pelos fotógrafos valoriza linhas paralelas, uma linguagem fotográfica que representa o trabalho humano, em contraposição às curvas da natureza, por essa razão, as linhas retas trazem representações da cidade ordenada.

Desta forma, há postais que fotografam apenas os edifícios, a prova cabal do domínio humano, como a Escola de Belas Artes do início do século XIX e o edifício A noite, construído já no alvorecer dos anos 1930, ou numa perspectiva mais ampla em que a Avenida seja enquadrada como um todo, sendo sua forma reta em destaque no enquadramento.

Além desses ícones espaciais e arquitetônicos, dois eventos foram importantes na construção da imagem da cidade e foram igualmente fundamentados através da cartofilia da época. Trata-se da Exposição Nacional de 1908 e Exposição Internacional de 1922 que ressaltam a paisagem da cidade como moldura para os pavilhões onde vislumbravam-se estilos arquitetônicos específicos. Foram encontrados muitos postais desses eventos.

A Exposição Nacional de 1908 foi realizada para comemorar o centenário da Abertura dos Portos às Nações Amigas, decretada por D. João, em 28 de janeiro de 1808. Ficou em aberta por 10 meses, na Praia Vermelha, Zona Sul do Rio de Janeiro, entre os morros da Babilônia e da Urca. Muitos postais desta exposição foram produzidos no período. O mesmo ocorreu com a Exposição Internacional de 1922 em comemoração ao Centenário de Independência do Brasil e que teve o intuito de exibir ao mundo os avanços da nação brasileira enquanto nação republicana (SANT'ANA, 2007).

Em especial, a Exposição Internacional de 1922 marca a perda do Morro do Castelo, arrasado por jatos d'água durante a administração do prefeito Carlos Sampaio em 1920. Não por acaso, a nova Esplanada do Castelo foi o palco escolhido para a edificação dos paviIhões da Exposição, pois, com o fim da mostra, a área resultante tornou-se muito valorizada. 
Próxima à Avenida Central, tal área seria loteada atendendo às necessidades, não somente de ordem higienista e estética, mas, sobretudo, da reprodução do capital (ABREU, 1997).

Fato curioso desta exposição nos foi apresentado por Gorberg (2002). Para a propaganda do evento publicou-se a revista $A$ exposição de 1922 e foram impressos cartões-postais que funcionavam como bônus. Assim, ao adquirir o postal, a pessoa ganhava acesso à exposição e concorria a sorteios. Este fato serve como fonte para nos indicar a popularidade dos postais na época num contexto de circulação interna (tanto na cidade quanto no país) e de promoção da imagem da cidade e consequentemente do Brasil, através de sua capital cosmopolita.

Em nossa pesquisa, nos chamou a atenção o grande número de postais que tinham como tema a paisagem do bairro de Botafogo. Desde o agora clássico ângulo da orla da praia de frente para o Pão de Açúcar, até os mais diversos posicionamentos da câmera do fotógrafo, o bairro é intensamente retratado (Figuras 7 e 8).

Lugar de moradia da chamada sociedade de maior poder aquisitivo e de políticos, o bairro tem seu crescimento acelerado com a reforma Pereira Passos quando ganha ares europeus, com novos jardins floridos.

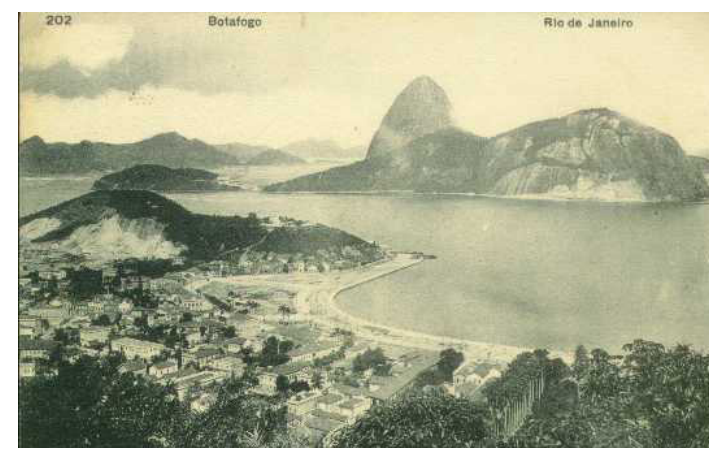

Figura 7 - Postal de Botafogo, Rio de Janeiro. Alexandre Ribeiro, 1903. BN.

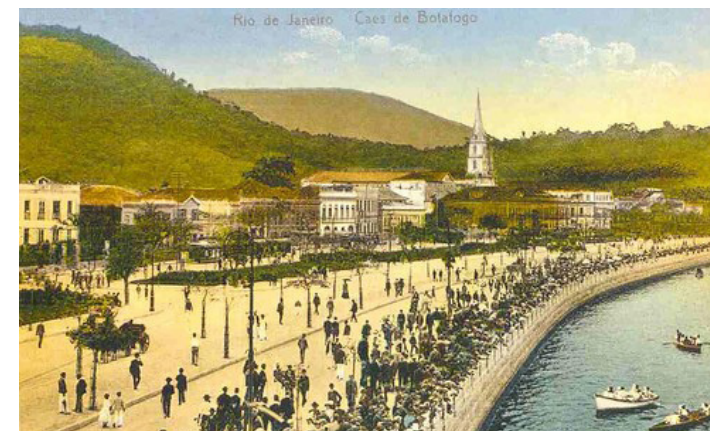

Figura 8 - Postal do Cais de Botafogo. Sem autor, por volta de 1915. AP. 
Na sua orla em 1915, já estava o muro de pedra arrematando o novo aterro feito (Figura 9). A praia não tinha mais areia, o que só surge novamente nos anos 1960 com Carlos Lacerda. A Figura 10 retrata um momento muito próprio vivido pelos moradores e frequentadores do bairro, um dia de regatas. Segundo Brasil (1965), a inauguração do Pavilhão de Regatas de Botafogo foi uma das grandes sensações de Pereira Passos. Esse prefeito é considerado um dos primeiros a fazer uso político da relação do esporte com a cidade, tornando o esporte um símbolo das mudanças que ele promoveu.

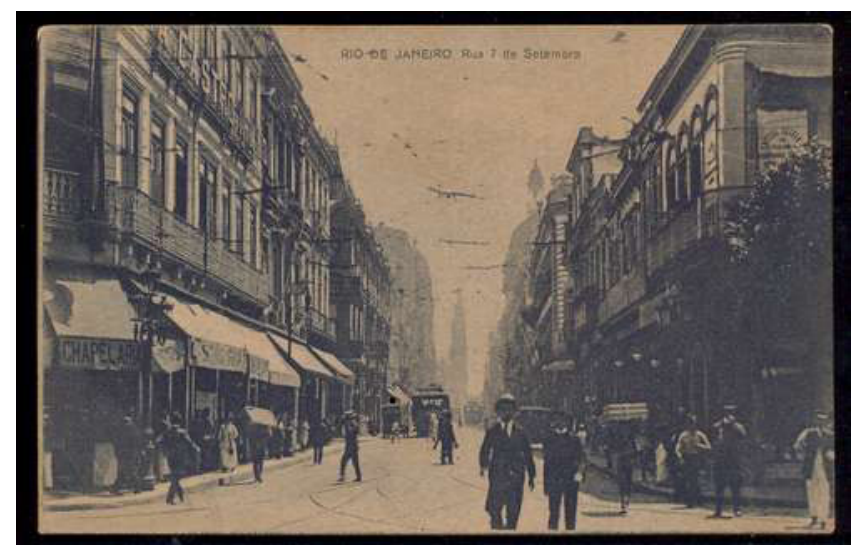

Figura 9 - Postal da Rua 7 de Setembro, RJ. Augusto Malta, s.d., por volta de 1910. AP.

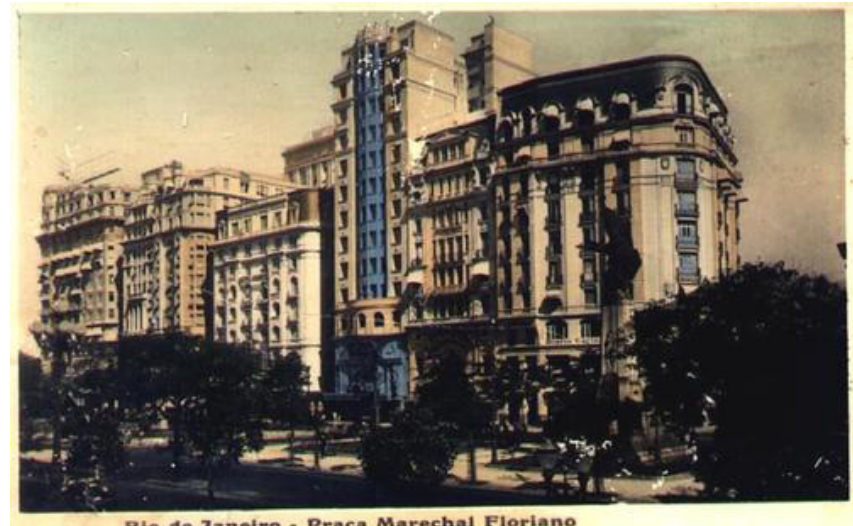

Rio de Janeiro - Praça Marechal Floriano

Figura 10 - Postal da Praça Marechal Floriano, RJ.

Sem autor, por volta de 1920. AP.

Desta forma, se até o fim do século XIX o turfe era a prática esportiva mais organizada e popular entre os cariocas, já na virada do século o remo, praticado desde os anos 1870, passou a ocupar o espaço na preferência pública. De acordo com Melo (2009), o público 
era atraído pelas competições mais acessíveis do que o turfe, pois eram realizadas nas praias. Porém, o autor destaca que os clubes de remo eram espaços restritos, assim, embora fosse um esporte popular, nem todos podiam praticá-lo. Assim, a prática do remo funciona como um padrão de vida civilizado e moderno. O remo seria o esporte que educa o músculo e a moral. Segundo Melo (2009), seus praticantes, geralmente filhos de profissionais liberais, militares, ou comerciantes, eram apresentados como exemplos a serem seguidos.

Por essas razões, encontramos um grande número de cartões-postais que tiveram como tema o bairro de Botafogo. Juntamente com aqueles que focalizavam o centro da cidade, esses postais estão transmitindo, através de seus signos, as ideias de paraíso morro do Pão de Açúcar - e civilização moderna - obras urbanas e práticas esportivas relacionando-as às ideias de higiene, saúde e progresso.

Por outro lado, a perspectiva de um plano médio e de um ângulo frontal, trata da escala local, a escolha do nível da rua e da valorização do espaço de experiência que convida o observador do postal a vivenciá-lo, pois é a partir da nova república, que haverá o deslocamento do espaço privado para o público. Segundo Carlos (1996), as ruas nos revelam formas de apropriações e temporalidades e guardam múltiplas dimensões e funções, podendo ter o sentido de passagem; o sentido de fim em si mesmas enquanto lócus para a reprodução do capital; o sentido de mercado, onde camelôs e feiras reúnem pessoas; o de festa; o de reivindicação; o de apropriação como território; e, por fim, o sentido de encontro. Encontramos postais de várias ruas no centro da cidade, entre elas, a rua 7 de Setembro, conforme mostra a Figura 9.

A câmera em pé, próxima à cena, valoriza as linhas da imagem que indicam movimento e vida. Além disso, o enquadramento da rua no centro na Figura 9 tem a função de ressaltá-la como o principal signo da fotografia que está registrando naquele momento a mudança do espaço privado para o público.

Outra característica da mensagem transmitida é o sentido de estabilidade e equilíbrio dado pela combinação retangular - horizontal - central. Podemos dizer, sobretudo nos postais do grupo "A cidade moderna", que encontramos nesta técnica uma tentativa de reforçar a ideia de uma pretensa estabilidade que só existiria na República, lembrando que parte do trabalho de Malta estava vinculado à "propaganda da República" no período em que este fotógrafo foi contratado por Pereira Passos para registrar o Rio de Janeiro antes e depois da reforma urbana.

O enquadramento frontal, onde o entorno do objeto é enfocado, também era considerado um elemento que compunha a cena e não somente algum complemento estético, para os fotógrafos, como Malta, que optavam por essa perspectiva. Nesse sentido, do lado esquerdo lê-se "chapelaria". Segundo Sevcenko (1989), o uso de chapéus funciona como símbolo de ingresso na civilização, além de significar toda uma regra de conduta e pertencimento a um seleto grupo social. Assim, temos representado na imagem uma parcela da sociedade que busca estar sempre em dia com a moda europeia.

Ademais, já que a rua é o local privilegiado da modernidade, tendo no seu símbolo máximo o automóvel, encontramos no hábito moderno e burguês de perambular pelos boulevards a existência de uma certa ociosidade. Mais do que isto, o ócio da população pobre caracterizava uma estagnação econômica, a ausência de trabalho; enquanto o burguês apenas colhia os frutos de seu esforço. Perambulando ele está economicamente 
ativo; o que se contrapõe à hora do trabalho não é, portanto, a hora do ócio, em seu sentido pejorativo, mas sim a hora do lazer e do consumo (ENTLER E OLIVEIRA JR, 2008).

Em outros postais, observamos a passagem para várias linhas de bonde, a Praça Tiradentes, antiga Praça da Constituição, foi um dos locais mais desenvolvidos para o lazer e a cultura, juntamente com a Praça Floriano Peixoto, chamada pelo povo de Cinelândia, centro da vida noturna nos anos 1920. Esses espaços aparecem prioritariamente num enquadramento de plano geral, com ângulo frontal ou ângulo plongêe (de cima para baixo). Ressaltam elementos como cafés, bares, bombonniéres, confeitarias, teatros etc. (Figuras 10 e 11).

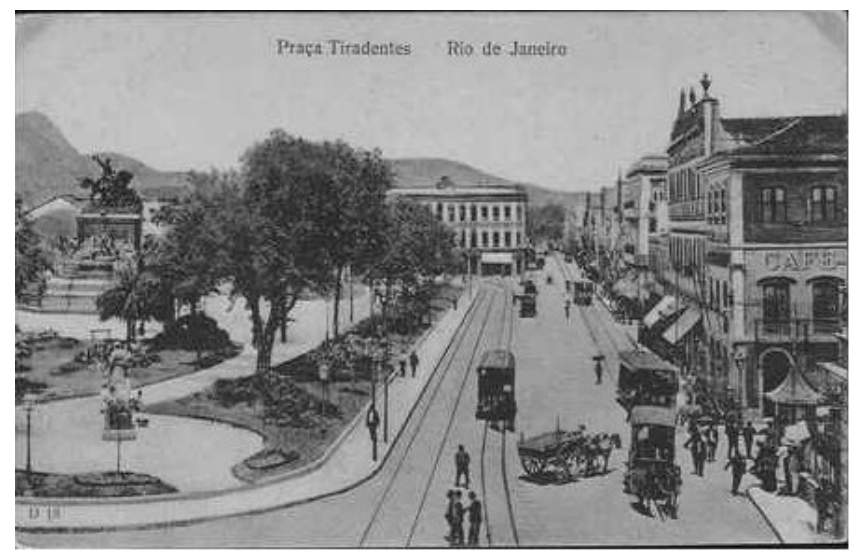

Figura 11 - Postal da Praça Tiradentes, RJ.

Sem autor, por volta de 1910. In: Gorberg (2002).

Desta forma, os cartões-postais estão exercendo o papel de reafirmar o caráter do espaço urbano, onde, nas calçadas desfilava-se a última moda e nos bancos dos jardins e das praças fervilhavam as notícias mais recentes. Vários postais da Praça da República, Praça 15 de Novembro, Praça Paris e Marechal Floriano com seus cinemas e todo o pulsar urbano estampado nas imagens também representam bem o aspecto da belle époque carioca.

Não apenas as reformas de Pereira Passos, mas também no governo de Frontim e Sampaio novas intervenções no espaço serviram para aprofundar as contradições existentes no sistema político e econômico do país, fincando as bases para o desenvolvimento do capital e para a passagem da cidade para a metrópole. Notoriamente, as reformas foram as primeiras ações estatais a promoverem a segregação sócio-espacial na cidade. Da mesma forma, os cartões-postais confirmaram essa segregação, ao excluir da imagem da cidade tudo aquilo que não era condizente com o ideário de vida moderna.

Não é por acaso que encontramos postais que dão visibilidade a obras da República, como a construção do Túnel novo, construção do viaduto da Estrada de Ferro Central e, ainda, rios canalizados como o Canal do Mangue ou canalização das águas no alto das Paineiras.

Ao fotografar as obras se escolhe o cenário ideal de uma situação que evidencie a competência do poder em direção ao progresso. A imagem, para o imaginário coletivo, remete ao sentido de segurança, estabilidade e desenvolvimento. "Nesse caso, tanto 
as fotografias de eventos cívicos quanto as do acompanhamento de obras públicas são exemplos típicos de tal mise-en-scène." (ESSUS, 2008, p. 290)

É nessa cidade cosmopolita que se inicia a construção de um grande signo tradicional nas paisagens dos cartões-postais cariocas que exibem sua natureza de maneira singular: o Pão de Açúcar.

O Pão de Açúcar, desde os primórdios da colonização, é um marco natural de destaque na entrada da Baía de Guanabara, servindo de referência para os navegadores. De acordo com Silva (1999), produziu-se diversos discursos sobre o Pão-de-Açúcar ao longo do tempo: marco de fundação da cidade, marco natural da cidade, marco da história da terra, graças a sua formação rochosa primitiva originada do resfriamento do magma. Encontramos ainda sua silhueta rendendo ideias como duas mãos voltadas para o céu, numa posição de oração, constituindo uma referência religiosa. Tudo isso contribuiu para a monumentalização do Pão de Açúcar. Sua paisagem se tornou verdadeiramente marca registrada da cidade com a construção do teleférico (mais conhecido como bondinho), em 1912, que trafega entre os morros, descortinando uma vista que exerce sempre fascínio entre cariocas e visitantes.

O caminho aéreo é na paisagem dos cartões-postais o símbolo da cidade moderna que é entendida não apenas pelas ações humanas, mas pela relação dessas ações com o meio físico. Desta forma, Silva (1999) defende o Pão de Açúcar e o bondinho como um duplo monumento, o primeiro doado pela natureza, e o segundo fruto da intervenção humana. Ousamos acrescentar a essa reflexão de Silva (1999) nossa compreensão de que o Pão de açúcar e seu caminho aéreo são o exemplo da paisagem alemã em que homem e natureza constituem uma só imagem. Assim, mais do que um duplo monumento, a visão dessa paisagem única da cidade é capaz de moldar, no imaginário dos habitantes, representações de uma cidade maravilhosa.

Tomando a parte pelo todo, a cidade do Rio de Janeiro seria a síntese do Brasil republicano e moderno que os postais, mais de 30 anos antes do hino oficial, já tentavam expor através das lentes dos fotógrafos. A "cidade maravilhosa, cheia de encantos mil", é aquela criada pelo progresso humano e sua técnica que transformou um meio hostil, pantanoso, malcheiroso, limitado por maciços, valorizada pela sua beleza cênica.

A exuberância dos elementos naturais não toca o observador pela sua magnificência, ou por seu romantismo, mas sim porque o prodigioso espetáculo natural é envolvido e dominado pela cidade do Rio de Janeiro. Se suas montanhas e seus mares existiam sempre, faltava naquele espaço o elemento integrador da ideia de paisagem na Alemanha do século XIX: o homem.

\section{Conclusão}

Ao interpretar a construção que se fez da imagem da Cidade de São Sebastião do Rio de Janeiro, o conceito de paisagem ligado às tradições do romantismo alemão muito nos serviu para compreender a paisagem dos cartões-postais como uma construção e reconstrução sobre a natureza atrelada aos valores culturais, sociais e ainda imateriais.

Por isso, o conceito que tão bem se desenvolveu na Alemanha romântica integra homem e natureza para poder definir a Landshaft. Esse homem, em nosso trabalho, 
apareceu de várias maneiras para olhar a paisagem do Rio de Janeiro. Um olhar que não é neutro, pois o que vemos ora nos agrada, ora nos incomoda, mas a todo o momento participa da experiência estética e emotiva dos lugares.

Assim temos, em primeiro lugar, a seletividade do fotógrafo. Homem que se posiciona com seu equipamento moderno para captar a imagem da cidade por intermédio de técnicas. Sua fotografia atuou como produtora e mediadora de hábitos e comportamentos; divulgou eventos, reformas urbanas e estilos arquitetônicos na cidade, espaço privilegiado pelos fotógrafos.

Em segundo lugar, a intencionalidade dos atores políticos, que, no período analisado, usaram a imagem da cidade como ponte para chegar a um ideário de nação republicana, nos moldes dos interesses capitalistas (evidenciada pela contração de Malta e Ferrez para fotografar o homem e sua obra, durante a gestão de Pereira Passos).

E, por último, o homem citadino, que qualificou e legitimou a cidade através dos seus usos. Esse mesmo homem, ao colecionar cartões-postais, criou um meio de preservar a memória, de pesquisar a história, de estudar a geografia e de vivenciar os usos e costumes das diferentes épocas.

Fonte iconográfica que nos atualiza de um passado através das formas espaciais. Nos postais, estamparam-se fotografias diversas, seleção de ângulos, alternativas e possibilidades, sendo, portanto, a própria escolha no ato de fotografar, índice do significado urbano a partir da produção de determinadas visibilidades da cidade tanto para o habitante quanto para o colecionador e, mais tarde, para o turista. O "ver" a cidade e o "viver o ver" a cidade se completaram na elaboração de uma identidade de cidade maravilhosa que valoriza o ser no lugar que, a partir da década de 1920, e, mais especificamente, no Estado Novo, somar-se-á aos atributos de ser carioca como um tipo humano que encerraria em si o povo brasileiro.

Mais do que a memória da cidade, lembranças eternizadas na paisagem, os cartões-postais, contribuíram para o desenrolar de uma corrente de pensamento contínuo que se estendeu pelos braços do imaginário social, para a formação da memória urbana. A fotografia conservou a memória da cidade que retifica a sua condição de "maravilhosa", deixando de fora tudo aquilo que não contribuía para esse padrão.

Fixos, fluxos, ideias, valores, simbolismo, tudo isso foi, no período de 1900 a 1935 , incorporado pelas imagens dos postais, nos ajudando, hoje, a contar uma história da cidade e uma geografia de suas formas simbólicas.

O evento da Rio-92, o sonho da candidatura do Rio de Janeiro como sede dos Jogos Olímpicos de 2004 e, novamente tentativas para 2012 e 2016, fizeram reacender as representações do passado da cidade, bem como o título de patrimônio mundial em 2012 na tipologia Paisagem Cultural que exemplifica a repetição da narrativa "entre o mar e a montanha" que faz do Rio de Janeiro a "cidade maravilhosa". De tempos em tempos, seja por ações estritamente políticas e econômicas, seja pela necessidade de autoestima, como desenvolvido por Lessa (2000), ou mesmo pelas práticas sociais de hoje, como, por exemplo, os aplausos no pôr do sol na praia de Ipanema, ou para o bondinho que passa no alto dos Arcos da Lapa; a ideia de Cidade Maravilhosa se refaz e revigora a imagem da cidade e do cidadão carioca e se torna a marca da cidade que o mundo inteiro reconhece.

Consideramos a paisagem um olhar cultural e, por consequência, a imagem fotográfica dos cartões-postais como símbolos da cultura. Esperamos que esta pesquisa possa ter 
contribuído com mais uma interpretação sobre a cidade do Rio de Janeiro, através das bases conceituais da geografia cultural. Longe de uma conclusão definitiva, gostaríamos de acreditar que apresentamos a imagem da cidade por meio de códigos do espetáculo, de seus símbolos da beleza - paraíso e progresso - que reproduziram nos cartões-postais um cenário ideal, onde se mostraram também ações sobre a cidade. Em suma, a visão da paisagem, poderá, muitas vezes, influenciar, ou mesmo, determinar, o tipo de uso a que determinado espaço urbano será destinado seja no passado com os cartões-postais ou hoje com outros suportes imagéticos.

\section{Referências Bibliográficas}

ABREU, M.A. A evolução urbana do Rio de Janeiro. Rio de Janeiro: IPLANRIO, 1997.

BERGER, P. O Rio de ontem no cartão-postal. 1900-1930. Rio de Janeiro: Rio Arte, 1983.

BRASIL, G. História das ruas do Rio de Janeiro. Rio de Janeiro: Brasiliana, 1965.

CARLOS, A.F.A. O Lugar no/do mundo. São Paulo: Hucitec, 1996.

CORBIN, A. Território do vazio: a praia e o imaginário ocidental. São Paulo: Ed. Companhia das Letras, 1989.

DIEGUES, A.C. Ilhas e mares: simbolismo e imaginário. São Paulo: Hucitec, 1999.

ENTLER, R.; OLIVEIRA JR., A.R. Augusto Malta e Marc Ferrez: olhares sobre a construção de uma metrópole. In: Revista 19\&20, Rio de Janeiro, v.III, n.4, out., 2008. Disponível em: <http://www.dezenovevinte.net/arte\%20decorativa/am_mf.htm>. Acesso em: 23 jan. 2009.

ESSUS, A.M.M.S.A. O espelho do poder: fotografia, sociabilidade urbana e representação simbólica do poder político no Rio de Janeiro da belle époque. In. SOUZA, C.F; PASSAVENTO, S.J. (Orgs.). Imagens urbanas: diversos olhares na formação do imaginário urbano. Porto Alegre: Editora da UFRGS, p. 281-292, 2008.

FERRARA, L. D'Aléssio. Ver a cidade. São Paulo: Nobel, 1988.

FREITAS, I.A.; PERES, W.R.; RAHY, I.S. A janela de Hitler. In: Revista GeoUerj. Rio de Janeiro, UERJ, n.6, jun-dez, p. 29-36, 1999.

GOMES, P.C.C. O lugar do olhar: elementos para uma geografia da visibilidade. Rio de Janeiro: Bertrand Brasil, 2013.

GORBERG, S. A propaganda no Brasil através do cartão-postal. 1900-1950. Rio de Janeiro:

S. Gorberb, 2002. 
LESSA, C. O Rio de todos os brasis: uma reflexão em busca de autoestima. Coleção Metrópoles. Rio de Janeiro: Record, 2000.

LOURENÇO, C. Paisagem no Kosmo de Humboldt: um diálogo entre abstração e sensibilidade. Tese (Doutorado em Geografia) - Faculdade de Filosofia, Letras e Ciências Humanos, Universidade de São Paulo: São Paulo, 2002.

MACHADO, M.B.T. A modernidade no Rio de Janeiro: construção de um cenário para o turismo. Rio de Janeiro: Secretaria Municipal das Culturas. Coordenadoria e documentação e informação cultural, 2008.

MELO, V.A. Músculos para o progresso. In. Revista de História da Biblioteca Nacional. n.22, jul., 2007. Disponível em: <http://www.revistadehistoria.com.br>. Acesso em: jun. 2009.

PEREIRA, A.M.M. O lazer no Rio de Janeiro visto pelo fotógrafo amador Alberto de Sampaio (1900-1910). In: Revista Urbana. Dossiê cidade, imagem, historia e interdisciplinaridade. Unicamp, ano 2, n.2, 2007.

RABHA, N.M.C.E. Centro do Rio: perdas e ganhos na história carioca. 2006. 603 f. Tese (Doutorado em Geografia) - PPGEO/Universidade Federal do Rio de Janeiro, 2006.

ROSE, G. Visual methodologies: an introduction to the interpretation of visual materials. London: Sage Publication, 2001.

SANT'ANA, T.R.S. Fincando Estacas: a exposição do centenário da independência do Brasil de 1922 nas fotografias da coleção Augusto César Malta de Campos pertencente ao Arquivo Histórico do Museu Histórico Nacional. In: Revista: 19 \& 20, Rio de Janeiro, vol. II, n.2, abril de 2007. Disponível em: <http://www.dezenovevinte.net/arte\%20decorativa/ expo_1922.htm>. Acesso em: 02 nov. 2008.

SEVCENKO, N. Literatura como missão: tensões sociais e criação cultural na Primeira República. São Paulo: Cia das Letras, 2003.

SILVA, R.A.S. O gigante e a máquina: Pão de Açúcar. In: KNAUSS, Paulo (Coord.). Cidade vaidosa: imagens urbanas do Rio de Janeiro. Rio de Janeiro: Sette Letras, p. 45-56, 1999.

VALLE, C.P. Risonhos lindos campos. Natureza tropical, imagem nacional e identidade brasileira. Rio de Janeiro: o autor, 2005.

Recebido em: 26/4/2016 Aceito em: 6/2/2017 